\title{
Premature Menopause
}

National Cancer Institute

\section{Source}

National Cancer Institute. Premature Menopause. NCI Thesaurus. Code C80099.

Cessation of menstruation before the age of 40 . Symptoms include hot flashes, night sweats, mood swings, and decreased sex drive. 